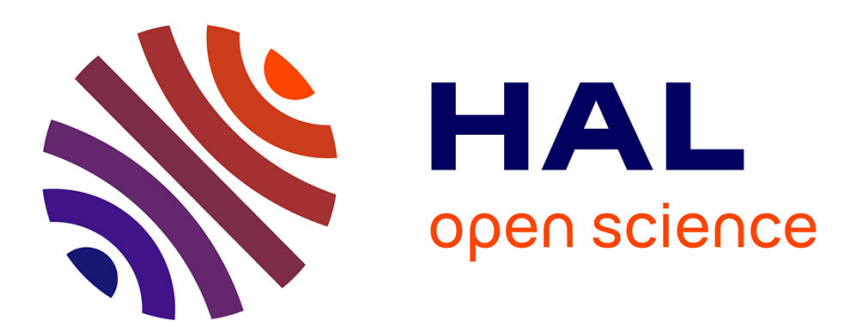

\title{
Influence of Quality of Recycled Concrete Aggregates Paste on the Internal Cure Phenomenon
}

Thibaut Marchi, Marie Salgues, Eric Garcia-Diaz, Jean-Claude Souche, Philippe Devillers

\section{To cite this version:}

Thibaut Marchi, Marie Salgues, Eric Garcia-Diaz, Jean-Claude Souche, Philippe Devillers. Influence of Quality of Recycled Concrete Aggregates Paste on the Internal Cure Phenomenon. ICCM 2021 - 11th ACI/RILEM International Conference on Cementitious Materials and Alternative Binders for Sustainable Concrete, Jun 2021, Online, France. hal-03263249

\section{HAL Id: hal-03263249 \\ https://hal.mines-ales.fr/hal-03263249}

Submitted on 2 Sep 2021

HAL is a multi-disciplinary open access archive for the deposit and dissemination of scientific research documents, whether they are published or not. The documents may come from teaching and research institutions in France or abroad, or from public or private research centers.
L'archive ouverte pluridisciplinaire $\mathbf{H A L}$, est destinée au dépôt et à la diffusion de documents scientifiques de niveau recherche, publiés ou non, émanant des établissements d'enseignement et de recherche français ou étrangers, des laboratoires publics ou privés. 


\title{
Influence of Quality of Recycled Concrete Aggregates Paste on the Internal Cure Phenomenon

\author{
Thibaut MARCHI ${ }^{A}$, Marie SALGUES ${ }^{A}$, Eric GARCIA DIAZ ${ }^{A}$, Jean Claude SOUCHE ${ }^{A}$, Philippe \\ DEVILLERS $^{B}$
}

\begin{abstract}
$A$ IMT Mines Alès, Centre des Matériaux de l'École des mines d'Alès, 6 av. de Clavières 30319 Alès cedex, France
\end{abstract}

$B$ LIFAM, ENSA de Montpellier, Univ Montpellier, France.

\begin{abstract}
:
Recent studies focused on the quality of the interfacial transition zone (ITZ) of ordinary concretes made from recycled aggregates (RA), without however focusing on High Performance Concretes (HPC).

This paper aims to formulate HPC from RA that are exclusively derived from concrete, whose composition is controlled. These concretes are made in a ready-mixed concrete plant and then undergo a crushing and riddling process to produce RA. Partially saturated gravels are substituted up to $100 \%$ in the HPC composition in order to accentuate internal cure phenomenon. This phenomenon was observed and demonstrated using a scanning electron microscope (SEM) in the low Water/Cement (W/C) paste up to a distance of $150 \mu \mathrm{m}$ from the RA and compared by image processing, to a reference concrete made from natural aggregates (NA).

The comparison of the mechanical performances and the microscopic analysis of HPC show that the characteristics transfer of the RA seem to favor a hydration of the paste by a mechanism of desorption of their absorbed water, in a process of "internal cure". The internal cure appears optimal for concrete C60. In addition to this observation, there was an increase in the strength of the recycled HPCs compared to control natural-aggregate HPCs.
\end{abstract}

Keywords: Recycling, durability, interfacial transition zone, internal curing, High Performance Concrete 


\section{INTRODUCTION}

The valorization of the materials resulting from the deconstruction represents a real challenge to preserve the natural resources and to limit the congestion of the storages areas of inert waste. The use of recycled aggregates (RA) in concrete depends on the quality of the concrete. The optimization of their recovery requires a selective treatment process in order to transform them into quality gravel used in concrete ([1] Cudeville).

Published papers show that the amount of cement paste in recycled material has a direct influence on the physical properties of recycled gravels, with an increase in the amount of water absorbed and a decrease in density [3](Pedro et al.). The higher strenght concrete of the source concrete, the higher the percentage of adhering paste to the RA after crushing [4]. The performance of recycled aggregates (RA) would decrease with the increase in the amount of paste adhering to natural aggregate [2]. Pedro et al (2014) have also studied the self-replicating capacity of RA -based concrete with the same performance as source concrete. They demonstrated that the quality of the recycled gravel depended on the performance of the "source concrete".

Because of their apparent porosity, the use of RA in the concrete mixture proportioning requires, for reasons of rheology and workability of the concrete, pre-saturation. The search carried out in the French national project Recybeton has made it possible to define optimal water content of RA from $80 \%$ of water absorption at $24 \mathrm{~h}$ (Wa24h) to $100 \% \mathrm{Wa} 24 \mathrm{~h}$ [6], [7]. The pre-saturation of the RA accentuates water exchanges between the RA and the cement paste, and consequently has an impact on the characteristics of the interfacial transition zone (ITZ) which characterizes these exchanges. Its quality is characterized by the porosity rate and the density of anhydrous observed with the scanning electron microscope on the periphery of RA [[20], [13], [12]]. The interfacial transition zone (ITZ) generally shows a region with poor properties because of its high porosity and stress concentrations causing microcracks [[9], [8], [10]]. Its thickness is from 10 to $50 \mu \mathrm{m}$ around natural aggregates [11], and would reach an average thickness of $55 \mu \mathrm{m}$ for recycled concretes [11]. This zone is a key factor directly influencing the concrete resistance [12]. Indeed, the porosity of the ITZ is higher than the one of the cement paste.

In 2004, Poon [13] worked on the influence of different types of RA on ITZ microstructure. The study revealed that the use of recycled gravel from HPC makes it possible to obtain an ITZ between the new and the old cement paste with microstructural properties superior to those obtained with RA from ordinary concretes. The paste quality of the source concrete influences the new ITZ (RA/new paste). According to [19], when the water ratio of the new and the old cement paste are less than 0.4 and 0.5 respectively, the ITZ is of good quality since the the old and the new cement paste adheres. The ITZ between cement paste and RA also determines the ability of a fluid to pass through concrete [14]. The quality of hydration of the paste beyond the ITZ, is more porous by the side effect, and has a tendency to decrease the permeability. E. Garcia-Diaz et al. [18] show that the water diffused by the recycled concrete aggregates (RCAs) contribute to the hydration of the cement paste by means of internal curing in low water/cement (W/C) ratio concretes that could be subject to self-desiccation.

The aim of this article is to experimentally highlight the internal curing phenomenon that appears at the interface between RA from ordinary concretes (OC) and High Performance Concretes (HPC). Knowing the mix-designs of recycled-based concretes, the purpose is to compare two different RA,on their inner curing capacity in concrete pastes achieving self-desiccation. The paper focuses on the characterization of the ITZ in order to qualify and quantify internal curing effects induced by the presence of water in the aggregates of recycled concrete that act, such as a water reservoir. Microscopic observation and the mechanical properties of these concretes based on recycled aggregates from different sources will be related. 


\section{MATERIALS AND METHODS}

The RA used in this paper are exclusively from two source concretes, representative of standard concrete used at building sites $(\mathrm{C} 25 / 30)$ or civil engineering infrastructure $(\mathrm{C} 40 / 50)$. These concretes, industrially produced in a ready-mixed concrete (RMC) plant were crushed and screened at the plant to obtain RAs of controlled composition and various granulometric sizes.

\section{Origin and characterization of recycled aggregates}

The two source concretes (SC) are respectively representative of a building concrete and a civil engineering one. They were made from a CEMI cement without addition of fines whose composition are detailed in Table 1 :

Table 1-ource concrete mixture proportioning

\begin{tabular}{|c|c|c|c|c|c|c|c|c|c|}
\hline Concrete & $\begin{array}{c}\text { Strength } \\
\text { class }\end{array}$ & $\begin{array}{c}F c_{28} \\
(M p a)\end{array}$ & $\begin{array}{c}\text { CEMI } \\
52,5 \mathrm{~N} \\
\left(\mathrm{~kg} / \mathrm{m}^{3}\right)\end{array}$ & $\begin{array}{c}W_{\text {eff }} \\
\left(\mathrm{kg} / \mathrm{m}^{3}\right)\end{array}$ & $\begin{array}{l}\text { 0/4 crushed } \\
\text { sand }\end{array}$ & $\begin{array}{c}0 / 4 \\
\text { mixed } \\
\text { river } \\
\text { sand }\end{array}$ & $\begin{array}{l}N A \\
4 / 16\end{array}$ & $\begin{array}{c}\text { superpla } \\
\text { sticizer }\end{array}$ & $W_{e f f} / C$ \\
\hline [SC-C25] & $\mathrm{C} 25 / 30$ & 30,80 & 300 & 187 & 514 & 431 & 1003 & - & 0,63 \\
\hline [SC-C40] & $\mathrm{C} 40 / 50$ & 49,50 & 461 & 200 & - & 814 & 1034 & 1,76 & 0,44 \\
\hline
\end{tabular}

The source concrete (SC) are made of crushed natural aggregates from the same origin. Because of the fresh concrete workability, SC-C25 concrete is composed of two sands, a crushed sand with fineness modulus of 3.10 (NF EN 12620 ) and a mixed river (alluvial and crushed mixture) sand with a fineness modulus of 3.31. SC-40 is composed only with mixed river sand.

The knowledge of the SCs composition allows us to precisely calculate the adherent paste content as well as its porosity accessible to water according to NF EN 1997-6 [Table 2]. The SCs have very different water contents, which result in different of $\mathrm{W}_{\text {eff/C. }}$. SC-C40 has a higher quantity of paste with higher density than SC-C25. These data justify the porosity difference between the pastes adhering to the aggregates.

The crushing process used consists of first reducing the blocks into pieces with a diameter of less than $800 \mathrm{~mm}$ using a hydraulic rock breaker and then crushing the blocks with an impact crusher (Metso - Lokotrack LT 1213S). Crushing associated with a screening phase has allowed the generation of granular classes compatible to the use in structural high performance concrete. This crusher design is well adapted for the treatment of a previously selected material [3] but its use is limited for the removal of contaminants attached to the parent concrete

The methods used to determine fragmentation resistance Los Angeles Index(LA Index) and saturated or nonsaturated attrition Indices Micro Deval (MDS \& MDE) were respectively compliant with standards NF EN 10972 and NF EN 1097-1, granulometric size 10/14, for all the aggregates. The characteristics of the aggregates and their adhesive paste are given in detail in [21] Marchi, $\mathrm{T}$, the main values which interest us in this article are presented in the Table 2.

Table 2-Characteristics of recycled aggregates and their adherent paste

\begin{tabular}{c|cccc|cc}
\hline Granulats & $\begin{array}{c}\text { Adhesive } \\
\text { paste in RA } \\
\text { (\%) }\end{array}$ & $\begin{array}{c}\text { Porosity of } \\
\text { adhesive } \\
\text { cement } \\
\text { paste }\end{array}$ & $\begin{array}{c}\text { Porosity } \\
\text { RA }\end{array}$ & WA24h RA & $\begin{array}{c}\text { LA index } \\
\text { (\%) }\end{array}$ & $\begin{array}{c}\text { MDE } \\
\text { index (\%) }\end{array}$ \\
\hline RA-C25 & 20 & $52 \%$ & $12 \%$ & $5,3 \%$ & $35 \%$ & $34 \%$ \\
RA-C40 & 27 & $42 \%$ & $13 \%$ & $4,9 \%$ & $34 \%$ & $23 \%$ \\
\hline
\end{tabular}

The characterization tests show a higher paste content for RA-C40 than RA-C25. On the other hand, RA-40 adherent cement paste is denser than the one of RA-C25 (1.57 against 1.35). These factors appear to be in equilibrium and give the RA a comparable resistance to fragmentation. These results are consistent with many research results and in particular [15] and [22]. 
The results of these macroscopic characterization tests show that the attrition rate (Micro Deval Index MDE) appears to be more related to the quality of the cement paste rather than its quantity. Indeed, the RA-C40 has an attrition rate lower than the RA-C25, despite a higher paste content because its cement paste quality is better.

\section{Composition of concretes prepared with recycled coarse concrete aggregates}

In order to highlight the ability of the RA to release water by internal curing of concretes subjected to selfdesiccation, low W/C concretes have been produced. The mixture proportions of these concrete are supplemented by standard ones useful for evaluating the influence on RA on the mechanical strengths and identifying the ceiling effects of the chippings. The four recycled concrete mix-design made are detailed in Table 3 and are compared to the reference concrete made from natural aggregates (NA). Except the recycled gravel (characterized above) substituted at $100 \%$ by natural gravels, except the coarse aggregates (NA or RA) the other components used are identical to those of C40/50 source concrete: mixed sand (0/4), CEMI type cement 52.5 without addition of fines, the superplasticizer. After completion of compactness tests and exploitation of the Dreux Gorisse curve, the Gravel/Sand volume ratio is set at 1.28 for C40, C60 and C80 concretes. For each mixture proportioning, the cement, sand and the effective water quantities are kept constant. RA-C25 and RA-C40 recycled aggregates are pre-saturated to $80 \% \mathrm{Wa} 24 \mathrm{~h}$. These concretes are casted in $11 \times 22$ cylinder specimens and are stored in water for 28 days at a controlled temperature of $20^{\circ} \mathrm{C}$.

Table 3-Recycled concrete mixture proportioning

\begin{tabular}{|c|c|c|c|c|c|c|c|c|c|c|c|c|}
\hline \multirow{2}{*}{$\begin{array}{l}\text { Concrete } \\
\text { mixture } \\
\text { proportions } \\
\text { (Kg } / \mathrm{m}^{3} \text { of } \\
\text { concrete) }\end{array}$} & \multicolumn{3}{|c|}{$\mathrm{C25}$} & \multicolumn{3}{|c|}{$\mathrm{C40}$} & \multicolumn{3}{|c|}{ C60 } & \multicolumn{3}{|c|}{$\mathrm{C80}$} \\
\hline & $N A$ & $R A C 25$ & $R A C 40$ & $N A$ & $R A C 25$ & $R A C 40$ & $N A$ & $R A C 25$ & $R A C 40$ & $N A$ & $R A C 25$ & $R A C 40$ \\
\hline NA (6/16) & 1033 & & & 981 & & & 1022 & & & 1076 & & \\
\hline $\operatorname{RAC} 25(5 / 14)$ & & 919 & & & 852 & & & 888 & & & 935 & \\
\hline $\operatorname{RAC} 40(5 / 14)$ & & & 900 & & & 834 & & & 870 & & & 914 \\
\hline $\begin{array}{l}\text { Mixed sand } \\
(0 / 4)\end{array}$ & 817 & 804 & 803 & 768 & 768 & 768 & 800 & 800 & 800 & 842 & 842 & 842 \\
\hline $\begin{array}{l}\text { Ciment CEM I } \\
52,5 \mathrm{~N}\end{array}$ & 305 & 305 & 305 & 439 & 439 & 439 & 457 & 457 & 457 & 481 & 481 & 481 \\
\hline $\begin{array}{l}\text { superplasticizer } \\
\text { Prémia } 180\end{array}$ & & & & 2.43 & 2.43 & 2.43 & 4.55 & 4.55 & 4.55 & 12 & 12 & 12 \\
\hline Efficient water & 188 & 181 & 181 & 188 & 182 & 183 & 155 & 150 & 150 & 112 & 110 & 110 \\
\hline $\mathrm{W}_{\text {eff }} / \mathrm{C}$ & 0.61 & 0.6 & 0.6 & 0.43 & 0.42 & 0.42 & 0,34 & 0,33 & 0,33 & 0.23 & 0.23 & 0.23 \\
\hline Entraped air $^{1}$ & $0.9 \%$ & $1.5 \%$ & $1.3 \%$ & $1 \%$ & $1.2 \%$ & $1.2 \%$ & $1 \%$ & $2 \%$ & $2 \%$ & $1 \%$ & $1 \%$ & $1 \%$ \\
\hline $\begin{array}{l}\text { Adhesive paste } \\
(\%)\end{array}$ & $30 \%$ & $35 \%$ & $36 \%$ & $34 \%$ & $34 \%$ & $34 \%$ & $32 \%$ & $31 \%$ & $31 \%$ & $28 \%$ & $27 \%$ & $27 \%$ \\
\hline
\end{tabular}

\section{Characterization of the anhydrous content by Scanning Electron Microscope and image processing}

The microstructural investigations consist of observing, using the SEM, the ITZ between the paste and the aggregates of the concrete samples. Four polished sections are observed for each concrete. Their sections are parallelepipedal, dimensions $1 \times 2 \times 2 \mathrm{~cm}^{3}$, and come from the core of concrete cylinder aged of 180 days. Their hydration was stopped by immersion for one week in a solvent (isopropanol-2). The solvent was removed by vacuum drying. In order to minimize the standard deviation and to obtain a representative analysis ([23] Thang Le), a dozen images have been taken using a FEA Quanta 200 FEG SEM coupled to an INCA X-sight Energy Oxford spectroscopic analyzer Dispersive X-ray (EDX), of these samples coated with carbon $(\sim 5 \mathrm{~nm})$. The imaging used is of the backscattered electron type (BSE), according to the protocol of [Scrivener and Gartner, 1987] and then analyzed with a scale of $200 \mu \mathrm{m}$ in order to detect elements of dimensions greater than $0.03 \mu \mathrm{m}^{2}$ and to evaluate the dispersion of the anhydrous.

The use of an image processing tool, illustrated in Fig. 1, allow us to quantify the variation of the anhydrous content in the cement paste as a function of the distance to the aggregate. The Matlab program developed by

\footnotetext{
${ }^{1}$ Air content of concrete regarding NF EN 12 350-7 -ISO 1920-2
} 
Tien Dung NGUYEN in his PhD permits identifying the thresholds of gray tints, to classify in particular the anhydrous ones. The inflection points of the grayscale histogram were used to determine the threshold of anhydrous and hydrated products. Fig. 1 below shows an example of a possible analysis:
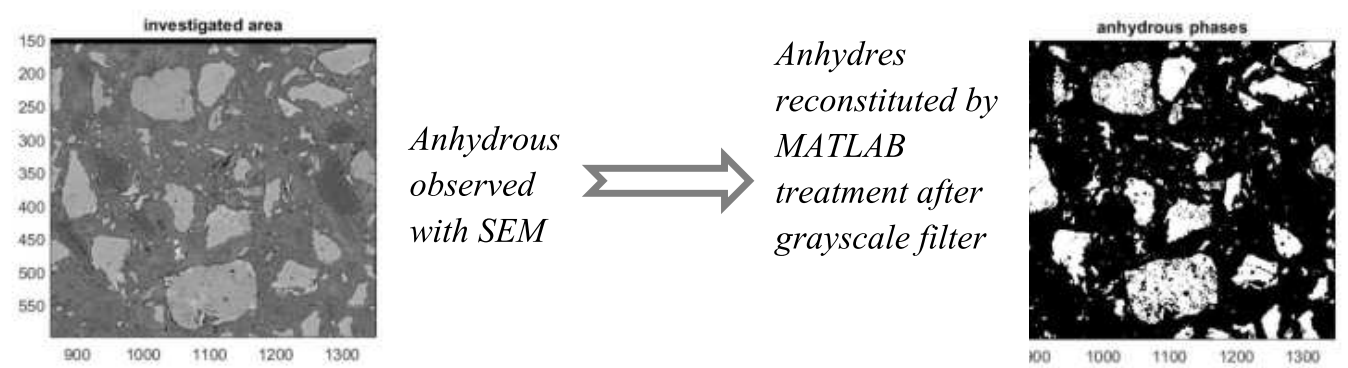

Fig. 1-Anhydrous observed with SEM - before and after image processing

\section{RESULTS}

The results are presented in the following order: the study of the concretes' compressive strength, then the microstructural study of the ITZ.

\section{Effect of aggregates on mechanical resistance of concretes}

Fig. 2 gives the compressive strengths at 28 days regarding $\mathrm{W}_{\text {eff }} / \mathrm{C}$. For each aggregate, the lower $\mathrm{W}_{\text {eff }} / \mathrm{C}$ ratio is 0,23, lighter is 0,60 . Except for $\mathrm{C} 60$, the recycled concretes have lower strength than the natural ones. The standard dispersion of the measured values increase slightly for high performance concretes, as shown in Fig. 2, however we note that the trend is still the same.

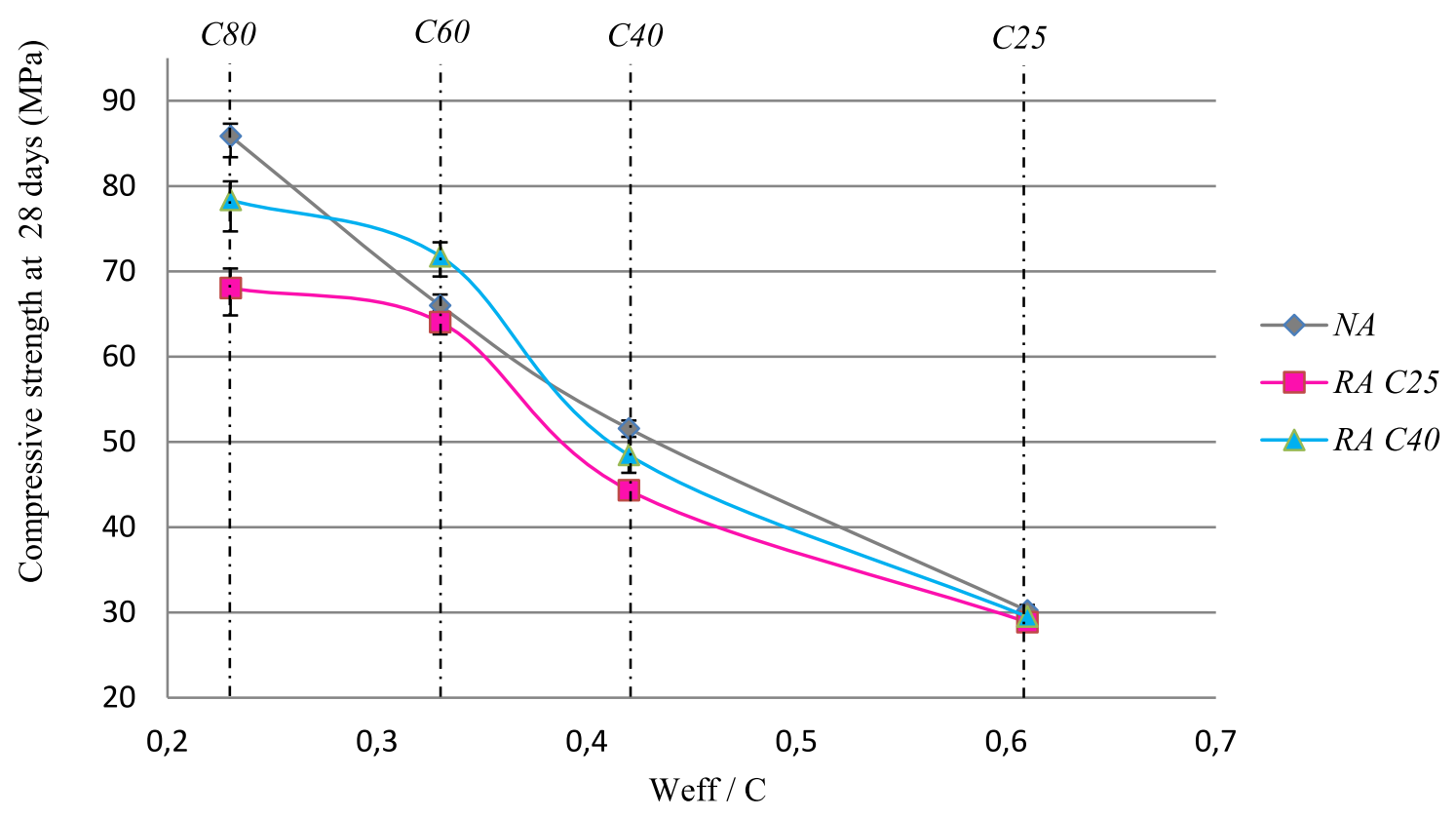

Fig. 2-Compressive strengths of concretes at 28 days

For OC, with $\mathrm{W} / \mathrm{C}$ ratio greater than 0.4 , the compressive strength of NA-based concretes are greater than ones of RA-based concretes. It appears in these compositions that the strength of concretes are directly correlated to the resistance of the SC : the RA-C40 base concrete are more resistant than the RA-C25 base concrete [Fig. 3]. This trend is also related to the attrition property values of these RA given in Table 2 and is consistent with the results of [16] Dao et al. 


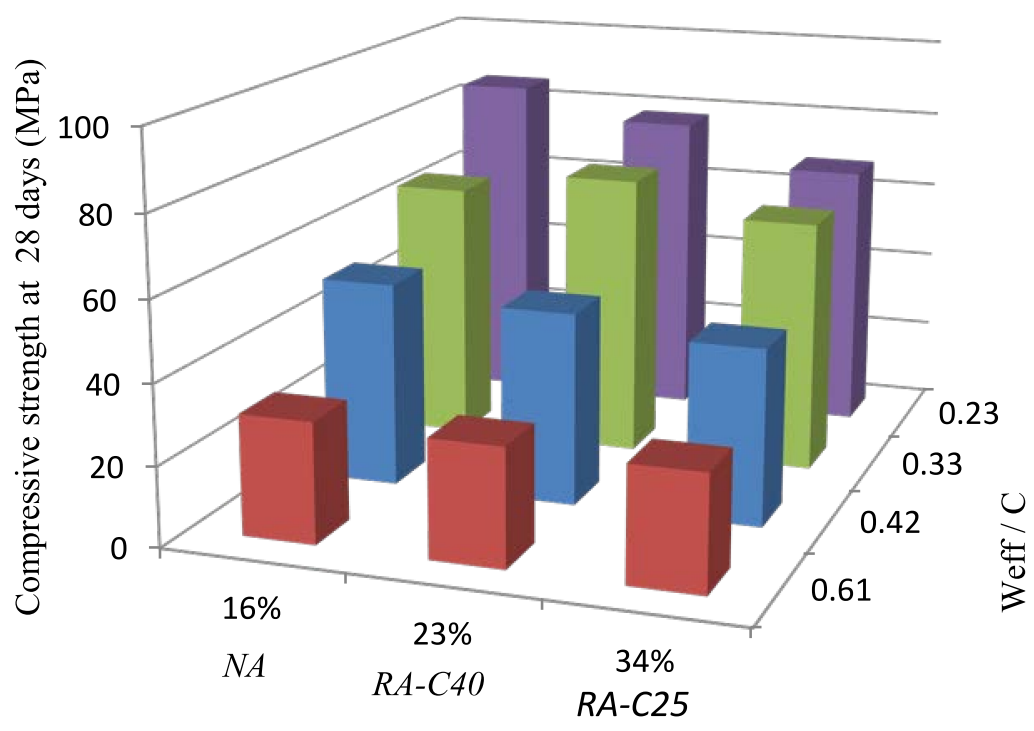

Attrition rate (Micro Deval Index MDE) \%

Fig. 3- Correlation between attrition rate of granulates and compressive strength of concretes

For HPC, with W/C ratio lower than 0.4 , it is necessary to differentiate concrete $\mathrm{C} 60$ (W/C equal to 0.33 ) and $\mathrm{C} 80$ (W/C equal to 0.25 ).

C60 based on RA are equivalent or better than C60 natural concrete, we remember that all C60 concretes have the same cement paste. So, the strength of concrete is not correlated with the strength of the aggregates: the C60RA-C40 has a higher resistance than the C60-NA. These results may be explained by an internal cure phenomenon improving the quality of the interface between the paste and the aggregates. This hypothesis is to be confirmed by microscopic analysis.

The mechanical performances of $\mathrm{C} 80$ using RA differ from the performance of NA-based concretes. For the C80-RA-C25 and C80-RA-C40 concretes, the resistances do not exceed $68 \mathrm{Mpa}$ and $78 \mathrm{Mpa}$, respectively, while that of C80-NA is equal to $86 \mathrm{Mpa}$. This might reflect the resistance threshold effect of aggregates according to the definition of [17] De-Larrard.

RA-based HPC seem to be singular points that deserve a detailed analysis of their microstructure using SEM to understand the mechanisms involved.

\section{ITZ observation}

The SEM observations are made at a scale of $200 \mu \mathrm{m}$ in order to observe the effects of the hydration of the paste over a representative distance with respect to the interface with the aggregates. The SEM observation of the ITZ for $\mathrm{C} 60$ and $\mathrm{C} 80$ concretes is illustrated in Fig. 4 and Fig. 5. 


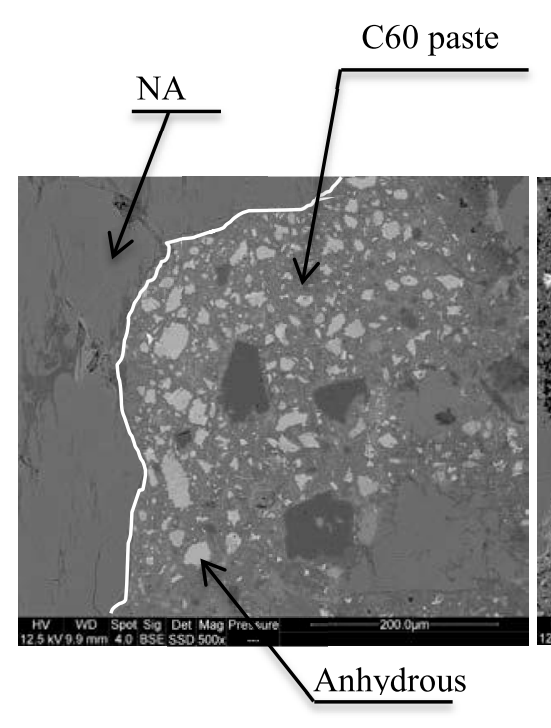

(a) $\mathrm{C} 60-\mathrm{NA}$

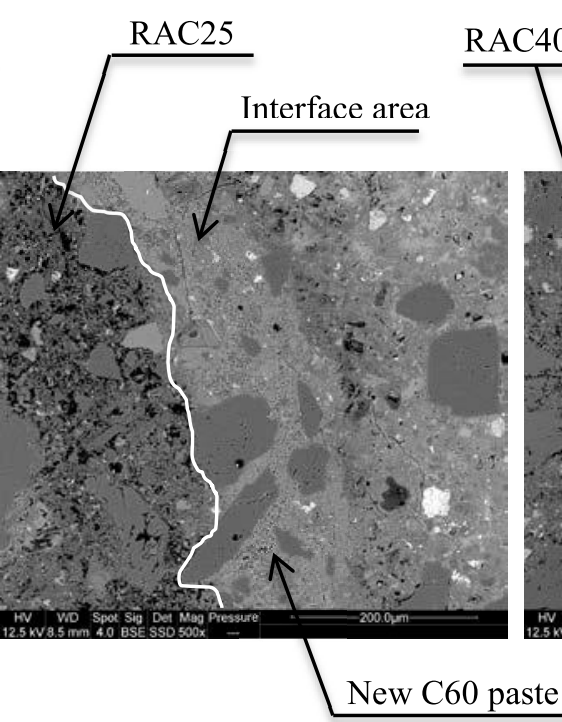

(b) C60-RAC25

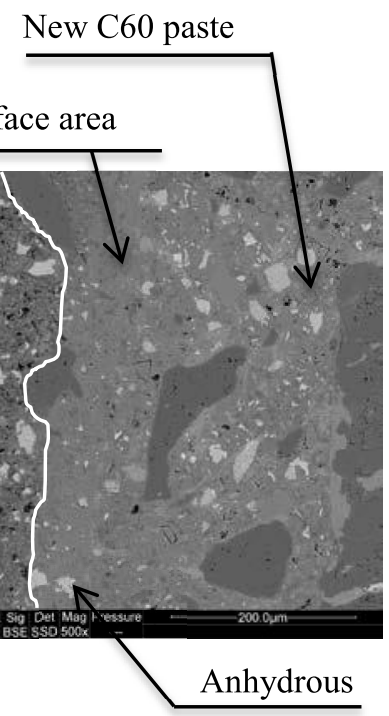

(c) C60-RAC40

Fig. 4-Photos of concrete samples C60 (W/C = 0.33) with Scanning Electron Microscope

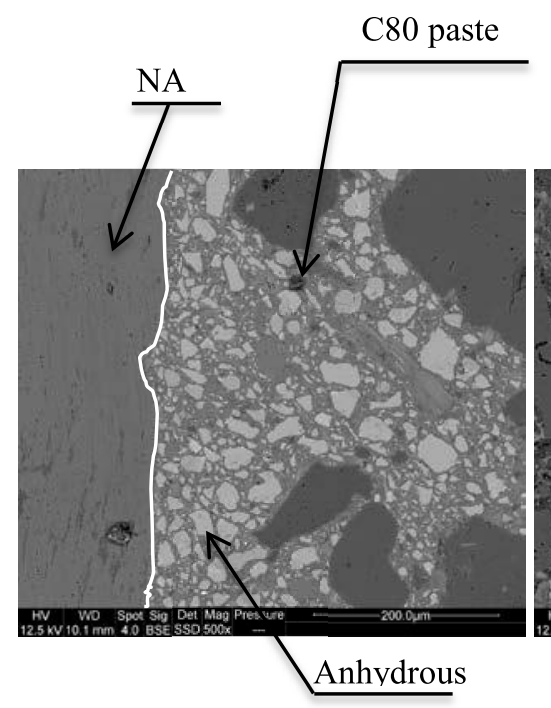

(a) $\mathrm{C} 80-\mathrm{NA}$

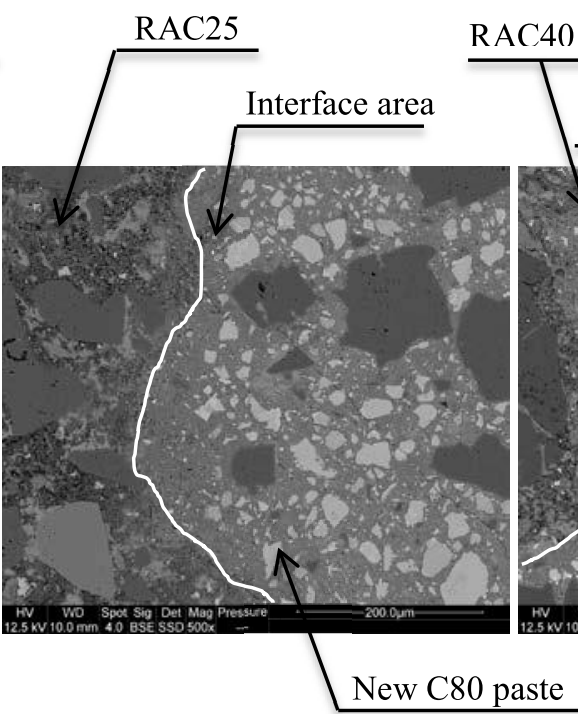

(b) C80-RAC25

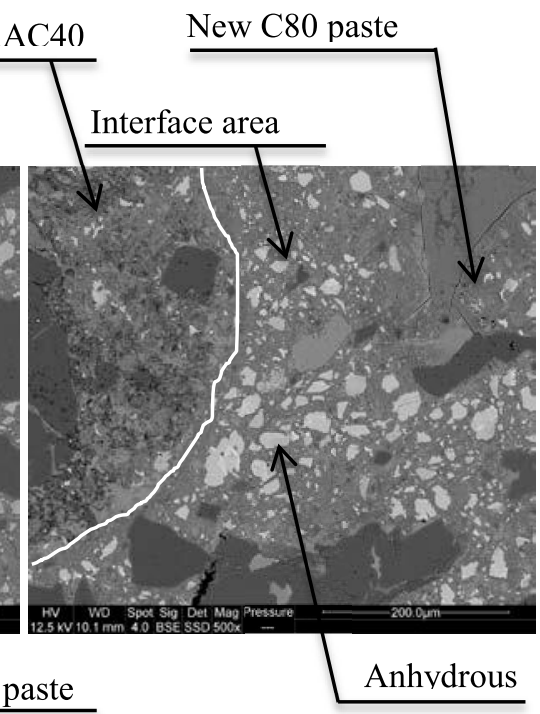

(c) C80-RAC40

Fig. 5-Photos of concrete samples C80 (W/C = 0.25) with Scanning Electron Microscope

The carried out observations show a clear distinction between the old paste and the new paste thanks to the different cement paste quality. The old cement paste is microporous while the new cement paste, denser and more efficient, is nano-porous. In Fig. 4 \& Fig. 5, the delimitation is marked by a white line.

According to what is observed, the C80 paste has more anhydrous than the C60 paste. NA-based concretes have a larger quantity of anhydrous than RA-based ones. This difference is more marked for the C60 than for the C80. This qualitative approach is completed by an image processing to quantify the proportion of anhydrous in these concretes. Indeed, the new low W/C paste has a nano-porosity whose variation remains difficult to observe at the SEM. Image processing using the Matlab software allows us to quantify the distribution of anhydrides in the paste of the HPC up to a distance of $150 \mu \mathrm{m}$ from the position of the granulate. 


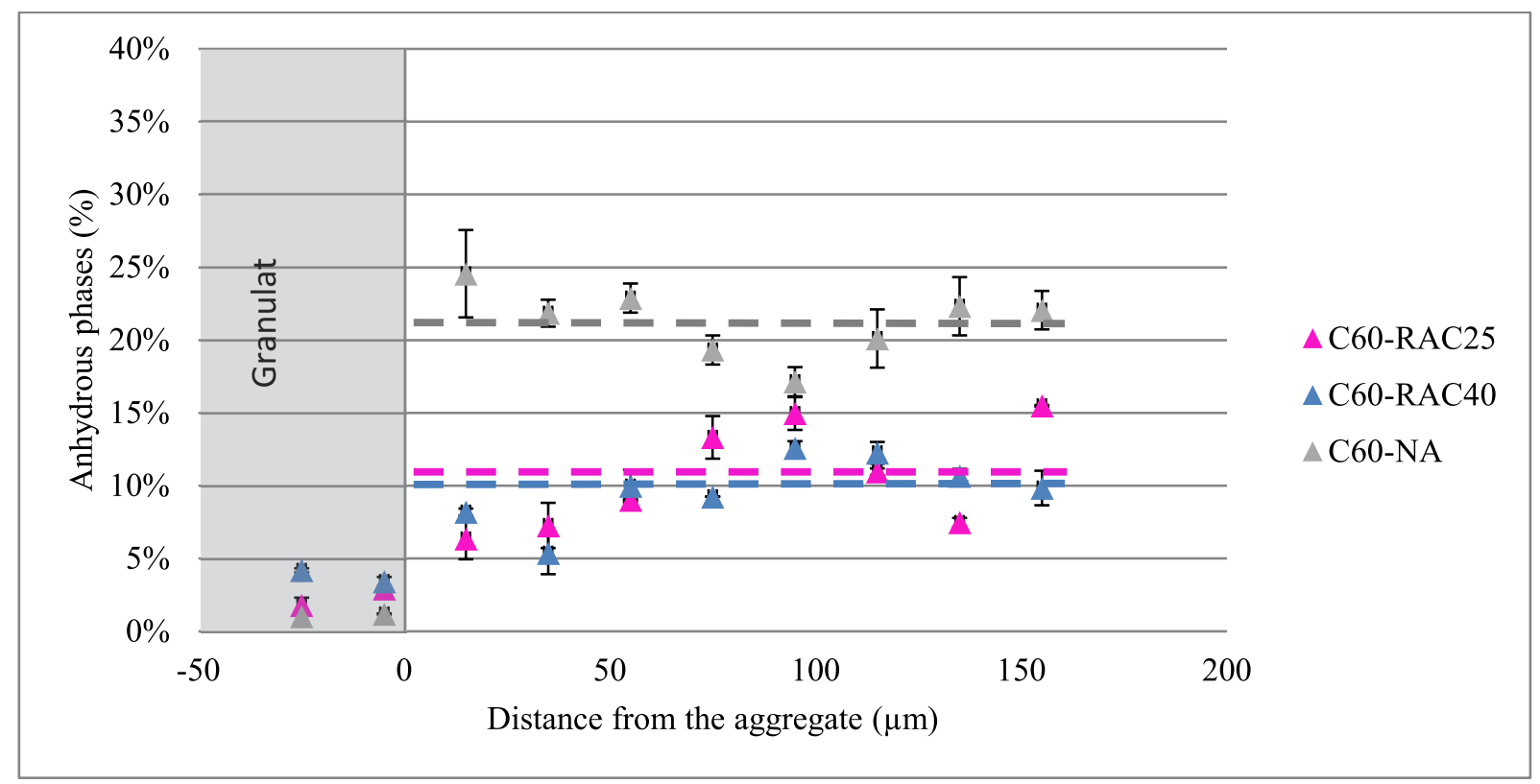

Fig. 6- Distribution of anhydrous phases in the ITZ between aggregate and C60 cement paste

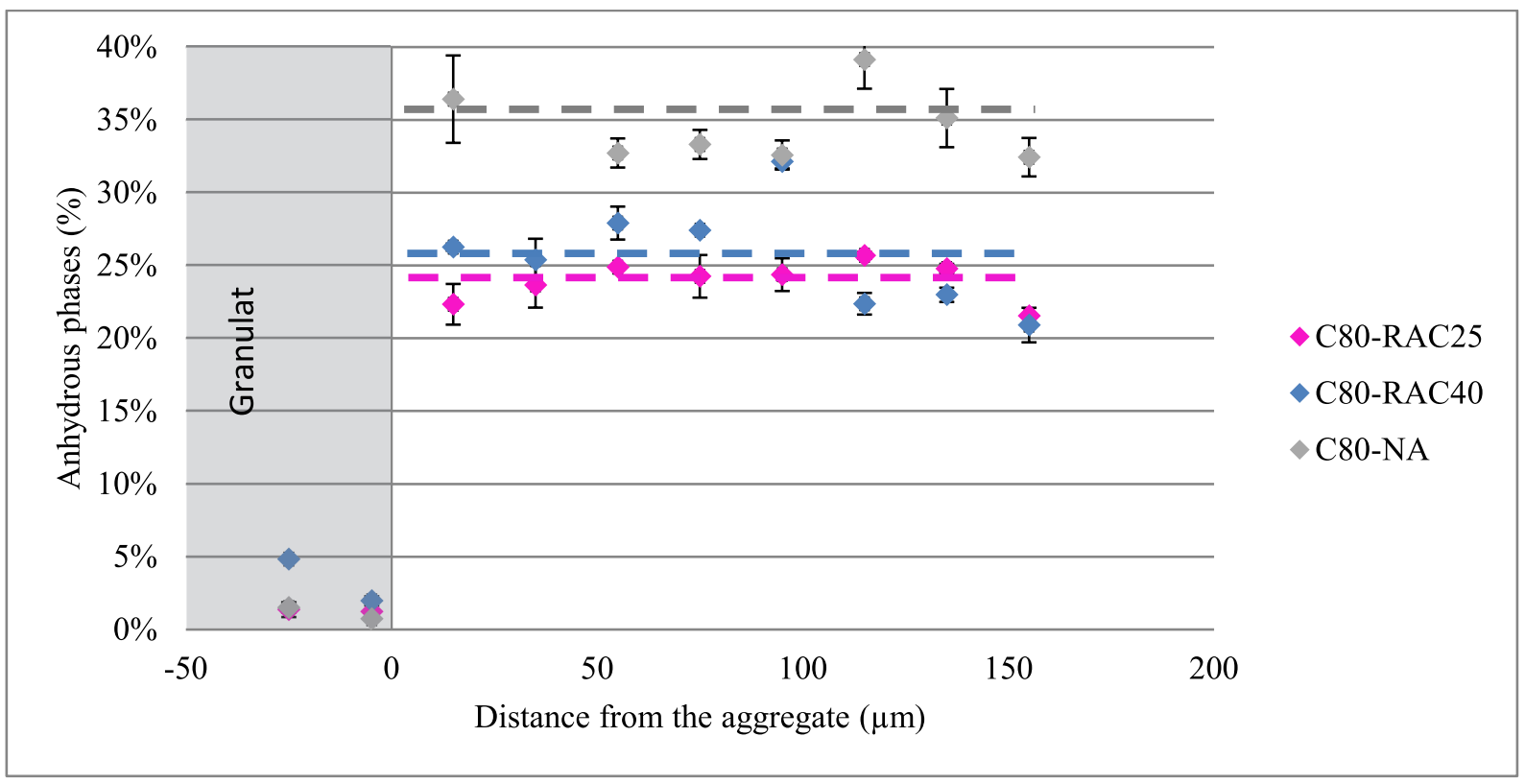

Fig. 7- Distribution of anhydrous phases in the ITZ between aggregate and C80 cement paste

NA-based concretes have a constant amount of anhydrous in HPC cement paste. 180 days old HPC has very little interface which corroborates the microstructural gradient distribution observed by [24] K.L. Scrivener.

Over a distance of $150 \mu \mathrm{m}$ from the gravel, a strong decrease of the anhydrous content in RA-based concretes appears. Fig. 6 \& Fig. 7 hightlights a well-marked hydration gradient over $100 \mu \mathrm{m}$ for the C60-RAC25 and the C60-RAC40. There is no significant difference between the anhydrous quantities and hydration capacities of the RAC25 and the RAC40.

These measurements reflect an internal curing effect of the concrete, from the available water stocked in the presaturated recycled aggregates, which release water via the interconnection of the porous network in the new cement paste.

Fig. 8 presents the mean proportion of anhydrous particles in the zone investigated ( 0 to $150 \mu \mathrm{m})$ in function of Weff/C. The resulting values are: 
- in the order of $20 \%$ for the C80 RA compared to $30 \%$ for the C 80 NA with Weff/C 0.23 ; i.e. 1.5 times higher for the NA concrete than the RA concrete

- in the order of $10 \%$ for the C60 RA compared to $20 \%$ for the C60 NA with Weff/C 0.33; i.e. twice as high for the NA concrete than the RA concrete

However, for a same concrete, there is no significant influence of the type of RA and the type of source concrete, on the microstructure of the new cement paste. This observation is only relative to the range of $\mathrm{W}_{\mathrm{eff}} / \mathrm{C}$ of the source concrete pastes considered in this study ([SC-C25]: Weff/C $=0.63$ and [SC-C40]: Weff/C $=0.44$ ).

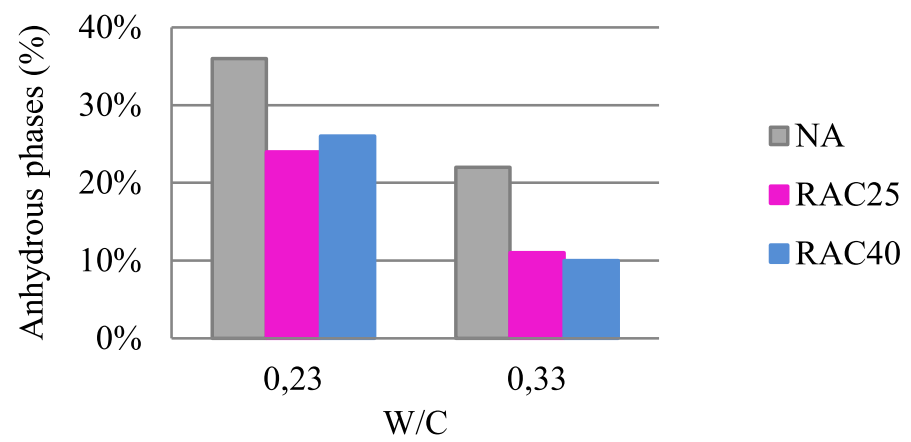

Fig. 8-Mean variation of the anhydrous content over $150 \mu \mathrm{m}$

These measurements can be explained by better hydration of the zone adjacent to the aggregate in the recycled C60 and C 80 concretes. So, the use of RA improves the paste hydration near RA for C80-RA and the C60-RA. It underlines an internal curing effect in the recycled concretes, where the stock of water available in the pores of the prewetted RA propagates via the interconnections of the pore network in the new cement paste.

This internal curing phenomenon seems to be higher marked in the RA-C60 concretes. We can suppose that the the lower capillary pores of the very low Weff/C pastes in the RA-C 80 concretes limit water transfer phenomena and therefore the internal curing secondary hydration process.

\section{CONCLUSIONS}

This paper highlights the phenomenon of internal curing generated by the use of recycled aggregates, derived from ordinary concrete and placed into paste poor in water $\left(\mathrm{W}_{\text {eff }} / \mathrm{C}\right.$ ratio less than 0.35$)$.

1. The internal cure phenomenon is demonstrated for both RA-based C60 and C80 concretes. The phenomenon seems to be higher for $\mathrm{C} 60$ concrete whose capillary network allows easily water transfer.

2. In the range of $\mathrm{C} 60$ concretes $(\mathrm{W} / \mathrm{C}=0.33)$, recycled aggregates from $\mathrm{C} 25$ or $\mathrm{C} 40$ source concretes make it possible to achieve mechanical strengths equal or better than natural concrete (NA being identical).

In the following research, it will be necessary to quantify the ratio between the internal curing and the shrinkage of self-desiccation which would also justify the improvement of the mechanical properties. The use of recycled sand in the formulation of these concretes remains to be tested, in order to homogenize the paste hydration of these concretes. 


\section{REFERENCES}

[1] Cudeville, A. (2011). Recycler le béton. Pour-La-Science, 408, 17-18.

[2] Pedro, D., De Brito, J., \& Evangelista, L. (2017). Structural concrete with simultaneous incorporation of fine and coarse recycled concrete aggregates: Mechanical, durability and long-term properties. https://doi.org/10.1016/j.conbuildmat.2017.07.215

[3] Silva, R. V., de Brito, J., \& Dhir, R. K. (2017). Availability and processing of recycled aggregates within the construction and demolition supply chain: A review. Journal of Cleaner Production, 143, 598-614. https://doi.org/10.1016/J.JCLEPRO.2016.12.070

[4] Akbarnezhad, A., Ong, K. C. G., Tam, C. T., \& Zhang, M. H. (2013). Effects of the Source Concrete Properties and Crushing Procedure on the Properties of Coarse Recycled Concrete Aggregates, (December), 1795-1802. https://doi.org/10.1061/(ASCE)MT.1943-5533.0000789.

[5] José M.VGómez-Soberón (2002). Porosity of recycled concrete with substitution of recycled concrete aggregate: An experimental study. https://doi.org/10.1016/S0008-8846(02)00795-0

[6] Mefteh, H, Kebaïli, O, Oucief, H, Berredjem, L, Arabi, N. 2013. Influence of moisture conditioning of recycled aggregates on the properties of fresh and hardened concrete. J.Clean. Prod. 54: 282-288.

[7] Poon, CS, Shui, ZH, Lam, L, Fok, H, Kou, SC. 2004. Influence of moisture states of natural and recycled aggregates on the slump and compressive strength of concrete. Cem. Concr. Res. 34: 31-36.

[8] Hanaa Khaleel AlwanAl-BayatiPrabir KumarDasSusan L.TigheHassanBaaj. (2016). Evaluation of various treatment methods for enhancing the physical and morphological properties of coarse recycled concrete aggregate. https://doi.org/10.1016/j.conbuildmat.2016.02.176

[9] Vivian W.Y.TamaC.M.TambY.Wangc (2007). Optimization on proportion for recycled aggregate in concrete using two-stage mixing approach. https://doi.org/10.1016/j.conbuildmat.2006.05.040

[10]LE, T. (2015). Absorption of recycled aggregates. PhD thesis. Ecole des Mines d'Alès - Ecole des Mines de Douai.

[11]Zhu, W., Howind, T., Matías, A., \& S, M. I. (2017). Properties of interfacial transition zones ( ITZs ) in concrete containing recycled mixed aggregate, 81. https://doi.org/10.1016/j.cemconcomp.2017.04.011

[12]Djerbi, A. (2018). Effect of recycled coarse aggregate on the new interfacial transition zone concrete Old paste Natural aggregate. Construction and Building Materials, 190, 1023-1033. https://doi.org/10.1016/j.conbuildmat.2018.09.180

[13]Poon, C. S., Shui, Z. H., \& Lam, L. (2004). Effect of microstructure of ITZ on compressive strength of concrete prepared with recycled aggregates, 18, 461-468. https://doi.org/10.1016/j.conbuildmat.2004.03.005

[14] Ollivier, J.-P., \& Torrenti, J.-M. (2008). The porous structure of concrete and the transfer properties. The durability of concrete. ENPC.

[15][Dao, 2012] Dao D.T., (Multi-) Concrete Recycling, PhD thesis, Ecole Centrale de Nantes, 2012.

[16][Dao et al., 2014] Dao D-T, Sedran T., de Larrard F., Optimization of the recycling of concrete in concrete: application to an airport slab, 12th international symposium on concrete road, Prague, Czech Republic, 23-26, 2014.

[17]Larrard, 1999] De Larrard F., Concrete Mixture-Proportioning: a scientific approach, Modern Concrete Technology, series No. 9, A. Bentur and S. Mindness editors, E \& FN SPON, ISBN 0-419-23500-0, 1999.

[18]E. Garcia-Diaz, A. Djerbi, G. Le Saout (2018), Microstructure of recycled concrete, Concrete Recycling, Research and Practice, Edited ByFrancois de Larrard, Horacio Colina

[19] Tan Li, Jianzhuang Xiao,Cimian Zhu (2016), Hydration process modeling of ITZ between new and old cement paste. Construction and Building Materials, https://doi.org/10.1016/j.conbuildmat.2016.01.053

[20]Nguyen, T. D., Le Saoût, G., Devillers, P., \& Garcia-diaz, É. (2014). The effect of limestone aggregate porosity and saturation degree on the interfacial zone.

[21] Marchi.T, Devillers P., Souche J-C, Salgues.M, Garcia-Diaz.E, Influence of source concrete on the quality of recycled aggregates, University, L. (2018). International Francophone Conference NoMaD 2018 Liège University, 1-12. https://popups.uliege.be/nomad2018/index.php?id=243\&file=1

[22] Akbarnezhad, A., Ong, K. C. G., Tam, C. T., \& Zhang, M. H. (2013). Effects of the Source Concrete Properties and Crushing Procedure on the Properties of Coarse Recycled Concrete Aggregates, (December), 1795-1802. https://doi.org/10.1061/(ASCE)MT.1943-5533.0000789.

[23]Thang Le, Gwenn Le Saout, Eric Garcia-Diaz, Damien Betrancourt, SébastienRémond. (2017) Hardened behavior of mortar based on recycled aggregate: Influence of saturation state at macro- and microscopic scale. https://doi.org/10.1016/j.conbuildmat.2017.02.035

[24]K. L. Scrivener, A. Bentur, P. L. Pratt. (1988) Quantitative characterization of the transition zone in high strength concretes. https://doi.org/10.1680/adcr.1988.1.4.230 